\title{
ĐÁNH GIÁ SỰ HÀI LÒNG CỦA NGƯỜI BẸNH VỀ CÔNG TÁC CHĂM SÓC CỦA ĐIËU DƯỠNG TẠI KHOA KHÁM BẸNH BẸNH VIẸN ĐA KHOA TİNH TUYÊN QUANG NĂM 2020
}

\author{
Hồ Phương Thúy ${ }^{1}$, Bàn Văn Hoàng ${ }^{1}$, Nguyễn Ngọc Anh ${ }^{1}$, Hà Xuân Kiên ${ }^{2}$ \\ ${ }^{1}$ Bệnh viện Đa khoa tỉnh Tuyên Quang; ${ }^{2}$ Trường Trung cấp Y tế Hà Giang
}

\section{TÓM TÁT}

Mục tiêu: Đánh giá sự hài lòng của người bệnh về chất lượng chăm sóc của Điều dưỡng tại Khoa Khám bệnh Bệnh viện Đa khoa tỉnh Tuyên Quang năm 2020. Đối tượng và phương pháp nghiên cứu: Mô tả cắt ngang được thực hiện trên 200 người bệnh đến khám tại Khoa Khám bệnh Bệnh viện Đa khoa tỉnh Tuyên Quang từ tháng 7/2020 đến tháng 9/2020. Sử dụng mẫu phiếu khảo sát sụ̣ hài lòng của người bệnh dụa theo hướng dẫn số 3869/QĐ-BYT ngày 28/8/2019 của Bộ Y tế. Kết quả: Tỷ lệ người bệnh hài lòng về công tác chăm sóc người bệnh của Điều dương là rất cao, dao động từ 95\% - 100\%. Tuy nhiên, vẫn còn một số người bệnh chưa hài lòng ở các tiêu chí: Đảm bảo sự riêng tư khi nằm viện như thay quần áo, khám bệnh, đi vệ sinh tại giường..., có rèm che, vách ngăn hoặc nằm riêng chiếm 5,0\%; Điều dưỡng tư vấn chế độ ăn, vận động, theo dõi và phòng biến chứng chiếm $5,0 \%$ và Điều dưỡng thực hiện thuốc đúng giờ chiếm $8,0 \%$. Kết luận: Cần thường xuyên giáo dục y đức, nâng cao giao tiếp, kỹ năng chăm sóc, tư vấn giáo dục sức khỏe cho Điều dưỡng, cung cấp đầy đủ cơ sở vật chất, hạ tầng và phương tiện phục vụ người bệnh.

Từ khóa: Sự hài lòng của người bệnh, công tác chăm sóc của Điều dướng, Bệnh viện Đa khoa tỉnh Tuyên Quang.

\section{ASSESSMENT OF PATIENT'S SATISFACTION REGARDING THE CARE OF NURSES AT THE DEPARTMENT OF OUT-PATIENTS OF TUYEN QUANG PROVINCIAL GENERAL HOSPITAL IN 2020}

\section{ASBTRACT}

Objective: To evaluation the patients' satisfaction about the quality of nursing care at the Department of Out-patients, Tuyen Quang Provincial General Hospital in 2020. Method: A cross-sectional description was performed among 200 patients who visited the Department of Out-patients of Tuyen Quang Provincial General Hospital from July 2020

Tác giả: Hồ Phương Thúy

Địa chỉ: Bệnh viện Đa khoa tỉnh Tuyên Quang Email: hophuongthuy9x@gmail.com
Ngày phản biện: 24/8/2021

Ngày duyệt bài: $27 / 8 / 2021$

Ngày xuất bản: 30/9/2021 
to September 2020. Using the patient satisfaction survey form according to the guidance No.3869/QĐ-BYT of the Ministry of Health. Results: The percentage of patients satisfied with the nursing care was very high, ranging from 95\% - 100\%. However, there were still some patients who were not satisfied with the following criteria: Ensuring privacy while in hospital such as changing clothes, examining a doctor, going to the toilet at the bed..., having curtains, partitions or sleeping separately 5.0\%; Nurses advising on diet, exercise, monitoring and preventing complications accounted for $5.0 \%$ and nurses on time taking medicine accounted for $8.0 \%$. Conclusion: It is necessary to regularly educate medical ethics, improve communication, care skills, provide health education counseling for nurses, provide adequate facilities, infrastructure and facilities to serve patients.

Keywords: Patient's satisfaction, nursing care, Tuyen Quang Provincial General Hospital

\section{1. ĐĂT VẤN ĐỀ}

Chất lượng dịch vụ chăm sóc sức khỏe (CSSK) hiện đang là một trong những mối quan tâm lớn của ngành y tế nói chung và các bệnh viện nói riêng bởi chất lượng kém sẽ ảnh hưởng trực tiếp đến tính mạng, sự hài lòng và chất lượng cuộc sống của người bệnh (NB). Chất lượng chăm sóc của Điều dưỡng (ĐD) là một phần quan trọng trong toàn bộ chất lượng dịch vụ chăm sóc y tế.

Tổ chức Y tế Thế giới đã nhận định dịch vụ CSSK do ĐD và hộ sinh cung cấp là một trong các trụ cột của hệ thống dịch vụ y tế. Hoạt động chăm sóc của ĐD trực tiếp tác động vào chất lượng điều trị [1]. Vì vậy, muốn nâng cao chất lượng dịch vụ y tế phải quan tâm nâng cao chất lượng và hiệu quả các dịch vụ chăm sóc Điều dưỡng (CSĐD) [2]. Chất lượng CSĐD là sự đáp ứng của ĐD về các nhu cầu thể chất, tinh thần, cảm xúc, xã hội và tâm lý của người bệnh (NB). Các nhu cầu đó được đáp ứng theo cách chăm sóc sao cho NB được chữa khỏi bệnh, khỏe mạnh, sống cuộc sống bình thường, cả ĐD và $\mathrm{NB}$ đều hài lòng [3]. CSĐD bắt đầu từ lúc NB đến khám, vào viện và cho đến khi NB ra viện hoặc tử vong. Nội dung chính bao gồm: chăm sóc thể chất, tinh thần, dinh dưỡng, lập kế hoạch chăm sóc, theo dõi, sử dụng thuốc, phục hồi chức năng và giáo dục sức khỏe cho NB [4]. Nhu cầu về dịch vụ chăm sóc có chất lượng ngày càng gia tăng ở mọi quốc gia, đặc biệt các quốc gia phát triển, do sự gia tăng dân số già làm tăng nhu cầu CSĐD tại nhà và các cơ sở y tế [5].

Sự hài lòng của NB ngày nay đã trở thành tiêu chí quan trọng trong việc đánh giá chất lượng bệnh viện theo quy định của Bộ $Y$ tế. Sự hài lòng của NB là ý kiến, cảm nhận, đánh giá của NB về công tác chăm sóc của ĐD mà họ nhận được khi đến khám, điều trị bệnh. Đánh giá sự hài lòng của NB với công tác CSĐD rất quan trọng nhằm mục đích nâng cao chất lượng khám chữa bệnh của cơ sở y tế. Sự hài lòng của NB dẫn đến quyết định lựa chọn cơ sở khám chữa bệnh, tạo nên mối quan hệ tốt với NB [6].

Trên thế giới đã có nhiều nghiên cứu về sự hài lòng của NB về công tác CSĐD. Như nghiên cứu của Shan L và cộng sự (2016) đánh giá sự hài lòng của NB về chăm sóc nội trú tại các bệnh viện ở Trung Quốc chỉ ra rằng có khoảng $24 \%$ NB không hài lòng với CSNB nội trú tại bệnh viện [7]. Bên cạnh đó, nghiên cứu của Aiken L.H và cộng 
sự (2017) thực hiện trên 66.348 NB tại các bệnh viện ở Anh cho thấy sự hài lòng của NB về chăm sóc bị giảm đáng kể do sự thiếu niềm tin vào $Đ D$ và do nhu cầu chăm sóc không được ĐD đáp ứng [8].

Tại Việt Nam, đã có nhiều tác giả nghiên cứu về sự hài lòng của NB nhưng phần lớn là nghiên cứu đánh giá sự hài lòng của NB về chất lượng khám chữa bệnh chung của bệnh viện. Chỉ một số ít nghiên cứu của Nguyễn Bá Anh (2014), Ngô Thị Lan Anh (2017) và Nguyễn Thị Dịu (2019) là đánh giá sự hài lòng của NB về công tác chăm sóc của $\bigoplus D$. Các nghiên cứu đã chỉ ra rằng, tỷ lệ hài lòng chung của NB với công tác CSĐD dao động từ 79,5\% - 91,0\%, những NB thuộc dân tộc thiểu số, trình độ học vấn thấp, tình trạng kinh tế gia đình khó khăn có sự hài lòng thấp về công tác chăm sóc của ĐD. Đồng thời, cũng có mối liên quan giữa ĐD luôn nhiệt tình ân cần đón tiếp với sự hài lòng chung của NB về công tác chăm sóc của ĐD [6], [9], [10].

Bệnh viện Đa khoa tỉnh Tuyên Quang là Bệnh viện Đa khoa tuyến tỉnh hạng I với quy mô 780 giường bệnh. Tổng số cán bộ viên chức, người lao động trong toàn bệnh viện tính đến thời điểm tháng 11 năm 2020 là 670 người: trong đó có 170 Bác sỹ, 308 Điều dưỡng, 26 Nữ hộ sinh và 51 Kỹ thuật viên. Khoa Khám bệnh của Bệnh viện có tổng số 29 người với 04 Bác sỹ và 25 Điều dưỡng. Trung bình mỗi ngày Khoa Khám bệnh tiếp nhận từ 600 - 700 người bệnh đến khám bệnh. Bệnh viện đã và đang thực hiện công tác chăm sóc của Điều dưỡng theo Thông tư 07/2011/TT-BYT ngày 26/01/2011 của Bộ $Y$ tế hướng dẫn công tác Điều dưỡng về chăm sóc người bệnh trong bệnh viện [11]. Để tìm hiểu rõ hơn về sự hài lòng của người bệnh về chất lượng chăm sóc của Điều dưỡng và phát hiện những tồn tại để có giải pháp điều chỉnh, chúng tôi tiến hành nghiên cứu: "Đánh giá sự hài lòng của người bệnh về chất lượng chăm sóc của Điều dưỡng tại Khoa Khám bệnh Bệnh viện Đa khoa tỉnh Tuyên Quang năm 2020" với mục tiêu: Đánh giá sự hài lòng của người bệnh về chất lượng chăm sóc của Điều dưỡng tại Khoa Khám bệnh Bệnh viện Đa khoa tỉnh Tuyên Quang.

\section{2. ĐÓI TƯƠ'NG VÀ PHƯO'NG PHÁP NGHIÊN CỨU}

\section{1. Đối tượng nghiên cứu}

Người bệnh đến khám bệnh tại Khoa Khám bệnh.

- Tiêu chuẩn lựa chọn: Người bệnh từ 18 tuổi trở lên. Người bệnh đến khám tại Khoa Khám bệnh và đã hoàn tất quy trình khám bệnh. Người bệnh đồng ý tham gia nghiên cứu.

- Tiêu chuẩn loại trừ: Người bệnh không có khả năng giao tiếp. Người bệnh là nhân viên y tế tại Bệnh viện.

\subsection{Thời gian và địa điểm}

- Thời gian nghiên cứu: Từ tháng 02 năm 2020 đến tháng 11 năm 2020.

- Thời gian thu thập và xử lý số liệu: Từ tháng 7 năm 2020 đến tháng 9 năm 2020.

- Địa điểm nghiên cứu: Tại Khoa Khám bệnh Bệnh viện Đa khoa tỉnh Tuyên Quang.

\subsection{Thiết kế nghiên cứu}

Nghiên cứu mô tả cắt ngang.

\subsection{Mẫu và phương pháp chọn mẫu}

Sử dụng phương pháp chọn mẫu toàn bộ, lấy tất cả người bệnh đến khám tại Khoa Khám bệnh Bệnh viện đa khoa 
tỉnh Tuyên Quang đáp ứng đầy đủ các tiêu chuẩn chọn mẫu và đồng ý tham gia nghiên cứu từ tháng 7 năm 2020 đến tháng 9 năm 2020. Thực tế, đã có 200 người bệnh đồng ý tham gia.

\subsection{Phương pháp thu thập số liệu}

Công cụ thu thập thông tin: Nghiên cứu sử dụng bộ câu hỏi tự điền đã chuẩn bị sã̃n, được xây dựng dựa trên hướng dẫn số 3869/QĐ-BYT ngày 28/8/2019 của Bộ Y tế [12]. Bộ câu hỏi bao gồm 03 phần:

- Phần I: Thông tin chung. Gồm 5 câu hỏi về thông tin của người bệnh tham gia nghiên cứu như năm sinh, giới tính, tôn giáo, tình trạng hôn nhân, trình độ học vấn.

- Phần II: Đánh giá sự hài lòng của người bệnh. Gồm 30 câu hỏi. Chia thành 5 tiểu mục:

+ Khả năng tiếp cận: Gồm 5 câu hỏi. Từ câu $A 1$ đến câu $A 5$.

+ Sự minh bạch thông tin và thủ tục khám bệnh, điều trị: Gồm 5 câu hỏi. Từ câu B1 đến câu B5.

+ Cơ sở vật chất và phương tiện phục vụ NB: Gồm 8 câu hỏi. Từ câu C1 đến câu C8.

+ Thái độ ứng xử, năng lực chuyên môn của ĐD: Gồm 5 câu hỏi. Từ câu D1 đến câu D9.

+ Kết quả cung cấp dịch vụ: Gồm 3 câu hỏi. Từ câu $\mathrm{E} 1$ đến câu E3.

Cách thu thập thông tin: Tại Khoa Khám bệnh, điều tra viên mời người bệnh đủ tiêu chuẩn lựa chọn, sau khi đã hoàn thành thủ tục thanh toán lên phòng riêng của khoa để tiến hành cuộc khảo sát. Điều tra viên giới thiệu mục đích của nghiên cứu, phát phiếu, hướng dẫn cách trả lời phiếu khảo sát theo quy định. Trong quá trình trả lời câu hỏi nếu người bệnh thấy nội dung nào chưa rõ hỏi trực tiếp điều tra viên để được giải thích. Sau khi trả lời xong phiếu điều tra, điều tra viên kiểm tra lại phiếu 1 lần nữa đảm bảo các thông tin được trả lời đầy đủ.

\subsection{Tiêu chí đánh giá trong nghiên cứu}

Đánh giá sự hài lòng của người bệnh tại Khoa Khám bệnh bao gồm 5 phần với tổng 30 câu hỏi nhỏ. Mỗi câu hỏi nhỏ được tính điểm bằng thang điểm Likert - type scale: Điểm 5: rất hài lòng; Điểm 4: hài lòng; Điểm 3: bình thường; Điểm 2: không hài lòng; Điểm 1: rất không hài lòng. Theo phân tích, suy luận logic với thang điểm Likert, thì mức hài lòng của NB bắt đầu từ mức 4 (4 điểm), vì thế thang điểm Likert được mã hóa thành hai nhóm: nhóm không hài lòng ( 1 - 3 điểm) và nhóm hài lòng (4 - 5 điểm) đối với từng câu hỏi.

\subsection{Phương pháp phân tích số liệu}

Sử dụng phần mềm thống kê SPSS phiên bản 20.0 .

\section{8. Đạo đức nghiên cứu}

Đối tượng nghiên cứu đồng thuận tham gia, các thông tin chỉ phục vụ nghiên cứu khoa học và được đảm bảo bí mật. Nghiên cứu đã được sự đồng ý cho phép thực hiện của Ban lãnh đạo Bệnh viện đa khoa tỉnh Tuyên Quang, lãnh đạo Khoa Khám bệnh và được thông qua Hội đồng $Y$ đức số 1388/QĐ-ĐDN ngày 15/6/2020 của Trường Đại học Điều dưỡng Nam Định.

\section{KÉT QUẢ}

\subsection{Thông tin chung về người bệnh tham gia nghiên cứu}


Bảng 1. Đặc điểm nhân khẩu học của người bệnh $(n=200)$

\begin{tabular}{|llcc|}
\hline & Thông tin & SL & $\%$ \\
\hline \multirow{3}{*}{ Nhóm tuổi } & $25-30$ tuổi & 28 & 14,0 \\
& $31-40$ tuổi & 129 & 64,5 \\
& $41-50$ tuổi & 35 & 17,5 \\
& $>50$ tuổi & 8 & 4,0 \\
\hline \multirow{2}{*}{ Giới tính } & Nam & 17 & 8,5 \\
& Nữ & 183 & 91,5 \\
\hline \multirow{3}{*}{ Tình trạng hôn nhân } & Độc thân & 5 & 2,5 \\
& Đã kết hôn & 182 & 91,0 \\
& Ly hôn/ly dị/góa & 13 & 6,5 \\
\hline \multirow{3}{*}{ Trình độ học vấn } & Trung cấp, Cao đẳng & 155 & 77,5 \\
& Đại học & 45 & 22,5 \\
& Sau đại học & 0 & 0 \\
\hline
\end{tabular}

Bảng 1 cho thấy: Người bệnh có độ tuổi từ 31 - 40 tuổi chiếm tỷ lệ cao nhất là 64,5\%; nhóm tuổi $>50$ tuổi có tỷ lệ thấp nhất là $4,0 \%$. Hầu hết NB tham gia nghiên cứu là nữ chiếm $91,5 \%$. Người bệnh có trình độ học vấn Trung cấp, Cao đẳng chiếm tỷ lệ cao nhất với $77,5 \%$.

\subsection{Thực trạng sự hài lòng của người bệnh tham gia nghiên cứu về công tác chăm sóc của Điều dưỡng}

Bảng 2. Sự hài lòng về khả năng tiếp cận của người bệnh $(n=200)$

\begin{tabular}{|lccccc|}
\hline \multicolumn{1}{|c}{ Tiêu chí } & \multicolumn{5}{c}{ Mức độ hài lòng (Số lượng (tỷ lệ)) } \\
& $\mathbf{1}$ & $\mathbf{2}$ & $\mathbf{3}$ & $\mathbf{4}$ & $\mathbf{5}$ \\
\hline $\begin{array}{l}\text { Các sơ đồ, biển báo chỉ dẫn đường đến } \\
\text { các khoa, phòng trong bệnh viện rõ ràng, } \\
\text { dễ hiểu, dễ tìm }\end{array}$ & $\begin{array}{c}0 \\
(0 \%)\end{array}$ & $\begin{array}{c}0 \\
(0 \%)\end{array}$ & $\begin{array}{c}1 \\
(0,5 \%)\end{array}$ & $\begin{array}{c}100 \\
(50,0 \%)\end{array}$ & $\begin{array}{c}99 \\
(49,5 \%)\end{array}$ \\
\hline $\begin{array}{l}\text { Thời gian vào thăm NB được thông báo } \\
\text { rõ ràng }\end{array}$ & $\begin{array}{c}0 \\
(0 \%)\end{array}$ & $\begin{array}{c}0 \\
(0 \%)\end{array}$ & $\begin{array}{c}1 \\
(0,5 \%)\end{array}$ & $\begin{array}{c}87 \\
(43,5 \%)\end{array}$ & $\begin{array}{c}112 \\
(56,0 \%)\end{array}$ \\
\hline $\begin{array}{l}\text { Các khối nhà, cầu thang, buồng bệnh } \\
\text { được đánh số rõ ràng, dễ tìm }\end{array}$ & $\begin{array}{c}0 \\
(0 \%)\end{array}$ & $\begin{array}{c}0 \\
(0 \%)\end{array}$ & $\begin{array}{c}2 \\
(1,0 \%)\end{array}$ & $\begin{array}{c}100 \\
(50,0 \%)\end{array}$ & $\begin{array}{c}98 \\
(49,0 \%)\end{array}$ \\
\hline $\begin{array}{l}\text { Các lối đi trong bệnh viện, hành lang bằng } \\
\text { phẳng, dễ đi }\end{array}$ & $\begin{array}{c}0 \\
(0 \%)\end{array}$ & $\begin{array}{c}0 \\
(0 \%)\end{array}$ & $\begin{array}{c}2 \\
(1,0 \%)\end{array}$ & $\begin{array}{c}91 \\
(45,5 \%)\end{array}$ & $\begin{array}{c}107 \\
(53,5 \%)\end{array}$ \\
\hline $\begin{array}{l}\text { Người bệnh hỏi gọi được nhân viên y tế } \\
\text { khi cần }\end{array}$ & $\begin{array}{c}0 \\
(0 \%)\end{array}$ & $\begin{array}{c}0 \\
(0 \%)\end{array}$ & $\begin{array}{c}0 \\
(0 \%)\end{array}$ & $\begin{array}{c}72 \\
(36,0 \%)\end{array}$ & $\begin{array}{c}128 \\
(64,0 \%)\end{array}$ \\
\hline
\end{tabular}

Ghi chú: 1. Rất Không hài lòng
4. Hài lòng
5. Rất hài lòng

2. Không hài lòng

3. Bình thường 
Kết quả bảng 2 chỉ ra: Hầu hết NB $(99,5 \%)$ hài lòng về các sơ đồ, biển báo chỉ dẫn đường đến các khoa, phòng trong bệnh viện rõ ràng, dễ hiểu, dễ tìm và thời gian vào thăm NB được thông báo rõ ràng. Tất cả NB $(100,0 \%)$ đều hài lòng về hỏi gọi được nhân viên $\mathrm{y}$ tế khi cần.

Bảng 3. Sự hài lòng về minh bạch thông tin và thủ tục khám chữa bệnh $(n=200)$

\begin{tabular}{|c|c|c|c|c|c|}
\hline \multirow{2}{*}{ Tiêu chí } & \multicolumn{5}{|c|}{ Mức độ hài lòng (Số lượng (tỷ lệ)) } \\
\hline & 1 & 2 & 3 & 4 & 5 \\
\hline $\begin{array}{l}\text { Quy trình thủ tục nhập viện rõ ràng, công } \\
\text { khai, thuận tiện }\end{array}$ & $\begin{array}{c}0 \\
(0 \%)\end{array}$ & $\begin{array}{c}0 \\
(0 \%)\end{array}$ & $\begin{array}{c}0 \\
(0 \%)\end{array}$ & $\begin{array}{c}80 \\
(40,0 \%)\end{array}$ & $\begin{array}{c}120 \\
(60,0 \%)\end{array}$ \\
\hline $\begin{array}{l}\text { ĐD đã phổ biến về nội quy và những } \\
\text { thông tin cần thiết khi nằm viện rõ ràng } \\
\text { đầy đủ }\end{array}$ & $\begin{array}{c}0 \\
(0 \%)\end{array}$ & $\begin{array}{c}0 \\
(0 \%)\end{array}$ & $\begin{array}{c}0 \\
(0 \%)\end{array}$ & $\begin{array}{c}84 \\
(42,0 \%)\end{array}$ & $\begin{array}{c}116 \\
(58,0 \%)\end{array}$ \\
\hline $\begin{array}{l}\text { ĐD đã giải thích về tình trạng bệnh, } \\
\text { phương pháp và thời gian dự kiến điều } \\
\text { trị rõ ràng, đầy đủ }\end{array}$ & $\begin{array}{c}0 \\
(0 \%)\end{array}$ & $\begin{array}{c}0 \\
(0 \%)\end{array}$ & $\begin{array}{c}0 \\
(0 \%)\end{array}$ & $\begin{array}{c}92 \\
(46,0 \%)\end{array}$ & $\begin{array}{c}108 \\
(54,0 \%)\end{array}$ \\
\hline $\begin{array}{l}\text { ĐD đã giải thích, tư vấn trước khi yêu } \\
\text { cầu làm các xét nghiệm thăm dò kỹ thuật } \\
\text { cao rõ ràng, đầy đủ }\end{array}$ & $\begin{array}{c}0 \\
(0 \%)\end{array}$ & $\begin{array}{c}0 \\
(0 \%)\end{array}$ & $\begin{array}{c}0 \\
(0 \%)\end{array}$ & $\begin{array}{c}78 \\
(39,0 \%)\end{array}$ & $\begin{array}{c}122 \\
(61,0 \%)\end{array}$ \\
\hline $\begin{array}{l}\text { ĐD đã công khai và cập nhật thông tin về } \\
\text { dùng thuốc và chi phí điều trị }\end{array}$ & $\begin{array}{c}0 \\
(0 \%)\end{array}$ & $\begin{array}{c}0 \\
(0 \%)\end{array}$ & $\begin{array}{c}0 \\
(0 \%)\end{array}$ & $\begin{array}{c}60 \\
(30,0 \%)\end{array}$ & $\begin{array}{c}140 \\
(70,0 \%)\end{array}$ \\
\hline
\end{tabular}
Ghi chú: 1. Rất Không hài lòng
4. Hài lòng
2. Không hài lòng
3. Bình thường
5. Rất hài lòng

Số liệu tại bảng 3 cho thấy: Tất cả đối tượng nghiên cứu (100,0\%) đều hài lòng về minh bạch thông tin và thủ tục khám bệnh điều trị cho NB.

Bảng 4. Sự hài lòng về cơ sở vật chất và phương tiện phục vụ NB $(n=200)$

\begin{tabular}{|c|c|c|c|c|c|}
\hline \multirow{2}{*}{ Tiêu chí } & \multicolumn{5}{|c|}{ Mức độ hài lòng (Số lượng (tỷ lệ)) } \\
\hline & 1 & 2 & 3 & 4 & 5 \\
\hline $\begin{array}{l}\text { Buồng bệnh nằm điều trị khang trang, } \\
\text { sạch sẽ, có đầy đủ các thiết bị điều chỉnh } \\
\text { nhiệt độ phù hợp như quạt, máy sưởi } \\
\text { hoặc điều hòa }\end{array}$ & $\begin{array}{c}0 \\
(0 \%)\end{array}$ & $\begin{array}{c}0 \\
(0 \%)\end{array}$ & $\begin{array}{c}0 \\
(0 \%)\end{array}$ & $\begin{array}{c}78 \\
(39,0 \%)\end{array}$ & $\begin{array}{c}122 \\
(61,0 \%)\end{array}$ \\
\hline $\begin{array}{l}\text { Giường bệnh, ga, gối đầy đủ cho mỗi } \\
\text { người một giường, an toàn chắc chắn, sử } \\
\text { dụng tốt (ga, gối được thay hàng ngày và } \\
\text { khi cần) }\end{array}$ & $\begin{array}{c}0 \\
(0 \%)\end{array}$ & $\begin{array}{c}0 \\
(0 \%)\end{array}$ & $\begin{array}{c}3 \\
(1,5 \%)\end{array}$ & $\begin{array}{c}69 \\
(34,5 \%)\end{array}$ & $\begin{array}{c}128 \\
(64,0 \%)\end{array}$ \\
\hline
\end{tabular}




\begin{tabular}{|c|c|c|c|c|c|}
\hline \multirow{2}{*}{ Tiêu chí } & \multicolumn{5}{|c|}{ Mức độ hài lòng (Số lượng (tỷ lệ)) } \\
\hline & 1 & 2 & 3 & 4 & 5 \\
\hline $\begin{array}{l}\text { Nhà vệ sinh, nhà tắm thuận tiện, sạch sẽ, } \\
\text { sử dụng tốt. }\end{array}$ & $\begin{array}{c}0 \\
(0 \%)\end{array}$ & $\begin{array}{c}0 \\
(0 \%)\end{array}$ & $\begin{array}{c}6 \\
(3,0 \%)\end{array}$ & $\begin{array}{c}114 \\
(57,0 \%)\end{array}$ & $\begin{array}{c}80 \\
(40,0 \%)\end{array}$ \\
\hline $\begin{array}{l}\text { Đã đảm bảo an toàn, an ninh trật tự phòng } \\
\text { ngừa trộm cắp, yên tâm khi nằm viện }\end{array}$ & $\begin{array}{c}0 \\
(0 \%)\end{array}$ & $\begin{array}{c}0 \\
(0 \%)\end{array}$ & $\begin{array}{c}4 \\
(2,0 \%)\end{array}$ & $\begin{array}{c}101 \\
(50,5 \%)\end{array}$ & $\begin{array}{c}95 \\
(47,5 \%)\end{array}$ \\
\hline $\begin{array}{l}\text { Đã cung cấp đầy đủ quần áo đầy đủ, sạch } \\
\text { sẽ (hàng ngày và khi cần) }\end{array}$ & $\begin{array}{c}0 \\
(0 \%)\end{array}$ & $\begin{array}{c}0 \\
(0 \%)\end{array}$ & $\begin{array}{c}0 \\
(0 \%)\end{array}$ & $\begin{array}{c}92 \\
(46,0 \%)\end{array}$ & $\begin{array}{c}108 \\
(54,0 \%)\end{array}$ \\
\hline $\begin{array}{l}\text { Đã cung cấp đầy đủ nước uống nóng, } \\
\text { lạnh }\end{array}$ & $\begin{array}{c}0 \\
(0 \%)\end{array}$ & $\begin{array}{c}0 \\
(0 \%)\end{array}$ & $\begin{array}{c}4 \\
(2,0 \%)\end{array}$ & $\begin{array}{c}95 \\
(47,5 \%)\end{array}$ & $\begin{array}{c}101 \\
(50,5 \%)\end{array}$ \\
\hline $\begin{array}{l}\text { Đã đảm bảo sự riêng tư khi nằm viện như } \\
\text { thay quần áo, khám bệnh, đi vệ sinh tại } \\
\text { giường..., có rèm che, vách ngăn hoặc } \\
\text { nằm riêng }\end{array}$ & $\begin{array}{c}0 \\
(0 \%)\end{array}$ & $\begin{array}{c}0 \\
(0 \%)\end{array}$ & $\begin{array}{c}10 \\
(5,0 \%)\end{array}$ & $\begin{array}{c}92 \\
(46,0 \%)\end{array}$ & $\begin{array}{c}100 \\
(50,0 \%)\end{array}$ \\
\hline $\begin{array}{l}\text { Môi trường trong khuôn viên bệnh viện } \\
\text { xanh, sạch đẹp. }\end{array}$ & $\begin{array}{c}0 \\
(0 \%)\end{array}$ & $\begin{array}{c}0 \\
(0 \%)\end{array}$ & $\begin{array}{c}1 \\
(0,5 \%)\end{array}$ & $\begin{array}{c}70 \\
(35,0 \%)\end{array}$ & $\begin{array}{c}129 \\
(64,5 \%)\end{array}$ \\
\hline
\end{tabular}

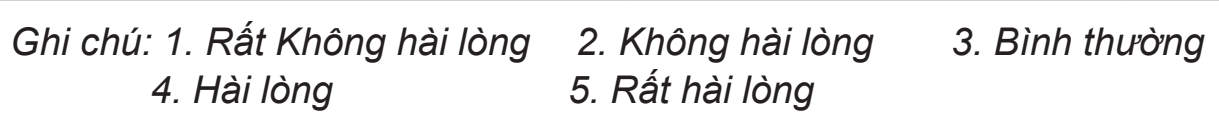

Kết quả bảng 4 chỉ ra: Về cơ sở vật chất và phương tiện phục vụ NB tỷ lệ hài lòng từ đối tượng nghiên cứu là rất cao, đặc biệt về tiêu chí buồng bệnh nằm điều trị khang trang, sạch sẽ, có đầy đủ các thiết bị điều chỉnh nhiệt độ phù hợp như quạt, máy sưởi hoặc điều hòa và tiêu chí đã cung cấp đầy đủ quần áo đầy đủ, sạch sẽ (hàng ngày và khi cần) đều đạt $100,0 \%$. Riêng tiêu chí đảm bảo sự riêng tư khi nằm viện như thay quần áo, khám bệnh, đi vệ sinh tại giường..., có rèm che, vách ngăn hoặc nằm riêng có $5,0 \%$ NB không hài lòng.

Bảng 5. Sự hài lòng về thái độ ứng xử, năng lực chuyên môn của ĐD $(\mathrm{n}=200)$

\begin{tabular}{|c|c|c|c|c|c|}
\hline \multirow{2}{*}{ Tiêu chí } & \multicolumn{5}{|c|}{ Mức độ hài lòng (Số lượng (tỷ lệ)) } \\
\hline & 1 & 2 & 3 & 4 & 5 \\
\hline ĐD có lời nói thái độ giao tiếp đúng mực & $\begin{array}{c}0 \\
(0 \%)\end{array}$ & $\begin{array}{c}0 \\
(0 \%)\end{array}$ & $\begin{array}{c}8 \\
(4,0 \%)\end{array}$ & $\begin{array}{c}42 \\
(21,0 \%)\end{array}$ & $\begin{array}{c}152 \\
(76,0 \%)\end{array}$ \\
\hline $\begin{array}{l}\text { Bác sỹ, ĐD hợp tác tốt và xử lý công việc } \\
\text { thành thạo, kịp thời }\end{array}$ & $\begin{array}{c}0 \\
(0 \%)\end{array}$ & $\begin{array}{c}0 \\
(0 \%)\end{array}$ & $\begin{array}{c}0 \\
(0 \%)\end{array}$ & $\begin{array}{c}34 \\
(17,0 \%)\end{array}$ & $\begin{array}{c}166 \\
(83,0 \%)\end{array}$ \\
\hline $\begin{array}{l}\text { ĐD tư vấn chế độ ăn, vận động, theo dõi } \\
\text { và phòng ngừa biến chứng }\end{array}$ & $\begin{array}{c}0 \\
(0 \%)\end{array}$ & $\begin{array}{c}0 \\
(0 \%)\end{array}$ & $\begin{array}{c}10 \\
(5,0 \%)\end{array}$ & $\begin{array}{c}42 \\
(21,0 \%)\end{array}$ & $\begin{array}{c}148 \\
(74,0 \%)\end{array}$ \\
\hline
\end{tabular}




\begin{tabular}{|c|c|c|c|c|c|}
\hline \multirow{2}{*}{ Tiêu chí } & \multicolumn{5}{|c|}{ Mức độ hài lòng (Số lượng (tỷ lệ)) } \\
\hline & 1 & 2 & 3 & 4 & 5 \\
\hline $\begin{array}{l}\text { ĐD thực nhiện tốt các quy trình kỹ thuật } \\
\text { tiêm, truyền, đo huyết áp... }\end{array}$ & $\begin{array}{c}0 \\
(0 \%)\end{array}$ & $\begin{array}{c}0 \\
(0 \%)\end{array}$ & $\begin{array}{c}0 \\
(0 \%)\end{array}$ & $\begin{array}{c}56 \\
(28,0 \%)\end{array}$ & $\begin{array}{c}144 \\
(72,0 \%)\end{array}$ \\
\hline ĐD thực hiện thuốc đúng giờ & $\begin{array}{c}0 \\
(0 \%)\end{array}$ & $\begin{array}{c}0 \\
(0 \%)\end{array}$ & $\begin{array}{c}16 \\
(8,0 \%)\end{array}$ & $\begin{array}{c}33 \\
(16,5 \%)\end{array}$ & $\begin{array}{c}151 \\
(75,5 \%)\end{array}$ \\
\hline $\begin{array}{l}\text { ĐD đo huyết áp, đếm mạch, nhịp thở } \\
\text { ít nhất } 1 \text { lần/ngày và khi cần, sau đo } \\
\text { thông báo kết quả cho NB biết và tư vấn, } \\
\text { hướng dẫn cho người bệnh những điều } \\
\text { cần thiết }\end{array}$ & $\begin{array}{c}0 \\
(0 \%)\end{array}$ & $\begin{array}{c}0 \\
(0 \%)\end{array}$ & $\begin{array}{c}6 \\
(3,0 \%)\end{array}$ & $\begin{array}{c}45 \\
(22,5 \%)\end{array}$ & $\begin{array}{c}149 \\
(74,5 \%)\end{array}$ \\
\hline $\begin{array}{l}\text { Trang phục của ĐD gọn gàng, sạch đẹp } \\
\text { không nhầu nát, đeo biển tên đầy đủ }\end{array}$ & $\begin{array}{c}0 \\
(0 \%)\end{array}$ & $\begin{array}{c}0 \\
(0 \%)\end{array}$ & $\begin{array}{c}0 \\
(0 \%)\end{array}$ & $\begin{array}{c}42 \\
(21,0 \%)\end{array}$ & $\begin{array}{c}158 \\
(79,0 \%)\end{array}$ \\
\hline ĐD không có biểu hiện gợi ý bồi dưỡng & $\begin{array}{c}0 \\
(0 \%)\end{array}$ & $\begin{array}{c}0 \\
(0 \%)\end{array}$ & $\begin{array}{c}0 \\
(0 \%)\end{array}$ & $\begin{array}{c}36 \\
(18,0 \%)\end{array}$ & $\begin{array}{c}164 \\
(82,0 \%)\end{array}$ \\
\hline
\end{tabular}
Ghi chú: 1. Rất Không hài lòng
4. Hài lòng
2. Không hài lòng
3. Bình thường
5. Rất hài lòng

Kết quả bảng 5 cho thấy: Về thái độ ứng xử, năng lực chuyên môn của Điều dưỡng tỷ lệ hài lòng của NB dao động từ 92,0\% - 100\%. Đáng chú ý ở tiêu chí ĐD tư vấn chế độ ăn, vận động, theo dõi và phòng ngừa biến chứng và tiêu chí ĐD thực hiện thuốc đúng giờ, tỷ lệ NB không hài lòng còn khá cao, với tỷ lệ tương ứng là 5,0\% và 8,0\%.

\section{Bảng 6. Sự hài lòng về kết quả cung cấp dịch vụ của Điều dưỡng $(\mathrm{n}=200)$}

\begin{tabular}{|c|c|c|c|c|c|}
\hline \multirow{2}{*}{ Tiêu chí } & \multicolumn{5}{|c|}{ Mức độ hài lòng (Số lượng (tỷ lệ)) } \\
\hline & 1 & 2 & 3 & 4 & 5 \\
\hline $\begin{array}{l}\text { Cấp phát thuốc và hướng dẫn sử dụng } \\
\text { thuốc đầy đủ, chất lượng }\end{array}$ & $\begin{array}{c}0 \\
(0 \%)\end{array}$ & $\begin{array}{c}0 \\
(0 \%)\end{array}$ & $\begin{array}{c}0 \\
(0 \%)\end{array}$ & $\begin{array}{c}86 \\
(43,0 \%)\end{array}$ & $\begin{array}{c}114 \\
(57,0 \%)\end{array}$ \\
\hline $\begin{array}{l}\text { Trang thiết bị, vật tư y tế đầy đủ, hiện đại, } \\
\text { đáp ứng nguyện vọng }\end{array}$ & $\begin{array}{c}0 \\
(0 \%)\end{array}$ & $\begin{array}{c}0 \\
(0 \%)\end{array}$ & $\begin{array}{c}0 \\
(0 \%)\end{array}$ & $\begin{array}{c}101 \\
(50,5 \%)\end{array}$ & $\begin{array}{c}99 \\
(49,5 \%)\end{array}$ \\
\hline $\begin{array}{l}\text { Kết quả điều trị đáp ứng được nguyện } \\
\text { vọng }\end{array}$ & $\begin{array}{c}0 \\
(0 \%)\end{array}$ & $\begin{array}{c}0 \\
(0 \%)\end{array}$ & $\begin{array}{c}0 \\
(0 \%)\end{array}$ & $\begin{array}{c}97 \\
(48,5 \%)\end{array}$ & $\begin{array}{c}103 \\
(51,5 \%)\end{array}$ \\
\hline
\end{tabular}
Ghi chú: 1. Rất Không hài lòng

$$
\text { 4. Hài lòng }
$$
2. Không hài lòng
3. Bình thường
5. Rất hài lòng

Số liệu tại bảng 6 cho thấy: Việc cấp phát và hướng dẫn sử dụng thuốc của điều dưỡng nhận được 43\% và 57\% người bệnh hài lòng và rất hài lòng. 


\section{BÀN LUẬN}

\subsection{Thông tin chung về người bệnh tham gia nghiên cứu}

Trong tổng số 200 NB tham gia nghiên cứu có 183 NB nữ (chiếm 91,5\%) và 17 nam (chiếm 8,5\%). NB có độ tuổi từ 31 - 40 tuổi chiếm tỷ lệ cao nhất $(64,5 \%)$; độ tuổi > 50 tuổi chiếm tỷ lệ thấp nhất $(4,0 \%)$. Trình độ chuyên môn của NB đa phần là Trung cấp, Cao đẳng $(77,5 \%)$.

4.2. Thực trạng sự hài lòng của người bệnh tham gia nghiên cứu về công tác chăm sóc của Điều dưỡng

\subsubsection{Sự hài lòng về khả năng tiếp cận của người bệnh}

Kết quả tại bảng 2 chỉ ra: Đa số NB $(99,5 \%)$ hài lòng và rất hài lòng về các sơ đồ, biển báo chỉ dẫn đường đến các khoa, phòng trong bệnh viện rõ ràng, dễ hiểu, dễ tìm và thời gian vào thăm người bệnh được thông báo rõ ràng. Có đến 99,0\% NB được hỏi đều có sự hài lòng cao với các khối nhà, cầu thang, buồng bệnh được đánh số rõ ràng, dễ hiểu. Tất cả người bệnh $(100,0 \%)$ đều hài lòng về người bệnh hỏi gọi được nhân viên $\mathrm{y}$ tế khi cần. Kết quả này khá tương đồng với nghiên cứu của tác giả Nguyễn Thị Tuyết Thanh thực hiện tại Khoa Khám bệnh Bệnh viện Phổi Trung ương năm 2019 với sự hài lòng về biển báo, chỉ dẫn $(85,46 \%)$ và với các khối nhà, cầu thang rõ ràng $(90,16 \%)$ [13]. Nhưng cao hơn so với tỷ lệ hài lòng với việc tiếp đón NB trong nghiên cứu của Bùi Thị Dương Vân (2011) tại Khoa Khám bệnh Bệnh viện Phổi Trung ương với tỷ lệ hài lòng về các bảng chỉ dẫn là $74,1 \%$ và về việc đi lại thuận tiện là $66,2 \%$ [14]. Do đó, nếu muốn tăng tỷ lệ hài lòng của NB hơn nữa, khâu đón tiếp NB và hướng dẫn các thủ tục liên quan là một mắt xích quan trọng mà bất cứ cơ sở $y$ tế nào cũng cần đầu tư và hoàn thiện.
4.2.2. Sự hài lòng về minh bạch thông tin và thủ tục khám bệnh cho người bệnh

Số liệu tại bảng 3 cho thấy: Ở 5 tiêu chí đánh giá về minh bạch thông tin và thủ tục khám bệnh điều trị cho NB thì tất cả NB tham gia nghiên cứu $(100,0 \%)$ đều hài lòng ở các tiêu chí này. Kết quả này cao hơn so với nghiên cứu của Nguyễn Thị Tuyết Thanh (2019) với tỷ lệ người bệnh hài lòng về việc thực hiện quy trình khám bệnh niêm yết rõ ràng; về giá dịch vụ y tế niêm yết công khai và về việc nhân viên giải thích thông tin cho người bệnh lần lượt là $84,79 \% ; 66,44 \%$ và $73,05 \%$ [13]. Thực tế, quy trình khám chữa bệnh và giá dịch vụ y tế được niêm yết công khai thể hiện sự minh bạch trong chuyên môn, NB yên tâm hơn khi chi trả viện phí, do đó sẽ hài lòng hơn.

\subsubsection{Sự hài lòng về cơ sở vật chất và} phương tiện phục vụ người bệnh

Đảm bảo vệ sinh, trật tự khoa phòng là một vấn đề đang được quan tâm ở hầu hết các bệnh viện tại Việt Nam. Với số lượng NB quá đông và cơ sở vật chất chưa đảm bảo thì duy trì khi vệ sinh cho người bệnh sạch sẽ luôn là một vấn đề dược chỉ ra ở phần lớn các nghiên cứu về sự hài lòng của người bệnh tại các bệnh viện ở Việt Nam.

Trong nghiên cứu của chúng tôi tỷ lệ NB hài lòng về cơ sở vật chất và phương tiện phục vụ NB rất cao, đặc biệt về tiêu chí buồng bệnh nằm điều trị khang trang, sạch sẽ, có đầy đủ các thiết bị điều chỉnh nhiệt độ phù hợp như quạt, máy sưởi hoặc điều hòa và tiêu chí đã cung cấp đầy đủ quần áo đầy đủ, sạch sẽ (hàng ngày và khi cần) đều đạt $100,0 \%$. Bên cạnh đó, vẫn còn $5,0 \%$ NB chưa thực sự hài lòng về đảm bảo sự riêng tư khi nằm viện như thay quần áo, khám bệnh, đi vệ sinh tại giường..., có rèm che, vách ngăn hoặc nằm riêng. Vấn đề này cần phải được Khoa Khám bệnh và bệnh viện 
quan tâm, cải thiện trong thời gian tới để nâng cao chất lượng phục vụ NB.

\subsubsection{Sự hài lòng của người bệnh về thái độ ứrng xử, năng lực chuyên môn của Điều dưỡng}

Tại Khoa Khám bệnh, người ĐD ngoài việc tiếp đón, động viên tinh thần và giữ mối quan hệ tốt với NB và người nhà NB và một số hoạt động chăm sóc thường xuyên phải thực hiện tốt bao gồm hướng dẫn, hỗ trợ NB đi làm các xét nghiệm cần thiết, giải thích và thông báo trước khi thực hiện các thủ thuật chăm sóc ban đầu. Bên cạnh đó, ĐD còn cần có chuyên môn để làm tốt các quy trình kỹ thuật của ĐD tại khoa, ví dụ như đo nhiệt độ, đo huyết áp, thực hiện thuốc, tư vấn chế độ ăn, vận động.... Những kỹ thuật này đòi hỏi người ĐD phải thực hiện một cách chuyên nghiệp, chính xác sẽ tạo được ấn tượng tốt với NB [6].

Trong nghiên cứu của chúng tôi, về thái độ ứng xử, năng lực chuyên môn của ĐD tỷ lệ hài lòng của NB dao động từ 92,0\% - 100\%. Cụ thể có tất cả NB $(100,0 \%)$ hài lòng về Bác sỹ, ĐD hợp tác tốt và xử lý công việc thành thạo, kịp thời; ĐD thăm khám, động viên hàng ngày tại phòng bệnh; ĐD thực nhiện tốt các quy trình kỹ thuật tiêm, truyền, đo huyết áp...; Trang phục của ĐD gọn gàng, sạch đẹp không nhầu nát, đeo biển tên đầy đủ và ĐD không có biểu hiện gợi ý bồi dưỡng. Kết quả này tương đồng với kết quả nghiên cứu của tác giả Nguyễn Thị Dịu (2019) tại Bệnh viện đa khoa Thái Thụy tỉnh Thái Bình với 100,0\% NB hài lòng về việc $Đ D$ thực hiện các quy trình kỹ thuật và 98,0\% người bệnh hài lòng về việc ĐD không có lời nói, biểu hiện sự gợi ý nhận quà, tiền [6]. Tuy nhiên, nghiên cứu của chúng tôi vẫn còn 5,0\% NB chưa thực sự hài lòng về ĐD tư vấn chế độ ăn, vận động, theo dõi và phòng ngừa biến chứng và $8,0 \%$ chưa thực sự hài lòng về ĐD thực hiện thuốc đúng giờ. Đây cũng là hai vấn đề cần phải được Khoa Khám bệnh quan tâm và cải thiện trong thời gian tới để tăng cường mức độ hài lòng của NB khi đến khám bệnh.

\subsubsection{Sự hài lòng của người bệnh về dịch vụ của Điều dưỡng}

Số liệu tại bảng 6 cho thấy: NB đánh giá rất cao ở cả 3 tiêu chí về cấp phát thuốc và hướng dẫn sử dụng thuốc đầy đủ, chất lượng; Trang thiết bị, vật tư y tế đầy đủ, hiện đại, đáp ứng nguyện vọng; Kết quả điều trị đáp ứng được nguyện vọng. Không có đối tượng nghiên cứu nào không hài lòng về cả 3 tiêu chí trên.

\section{KÉT LUÂN}

Tỷ lệ người bệnh hài lòng về công tác chăm sóc của Điều dưỡng là rất cao, dao động từ 95\% - 100\%. Tuy nhiên, vẫn còn một số người bệnh chưa hài lòng ở các tiêu chí: Đảm bảo sự riêng tư khi nằm viện như thay quần áo, khám bệnh, đi vệ sinh tại giường..., có rèm che, vách ngăn hoặc nằm riêng chiếm $5,0 \%$; Điều dưỡng tư vấn chế độ ăn, vận động, theo dõi và phòng biến chứng chiếm $5,0 \%$ và Điều dưỡng thực hiện thuốc đúng giờ chiếm 8,0\%. Cần thường xuyên giáo dục y đức, nâng cao giao tiếp, kỹ năng chăm sóc, tư vấn giáo dục sức khỏe cho Điều dưỡng, cung cấp đầy đủ cơ sở vật chất, hạ tầng và phương tiện phục vụ người bệnh.

\section{TÀI LIẸU THAM KHẢO}

1. Dogan $\mathrm{T}$, Tugut $\mathrm{N}$ and Golbasi $\mathrm{Z}$ (2013). The relationship between sexual quality of life, happiness, and satisfaction with life in married Turkish women. Sexuality and Disability; 31(3), 239-247. 
2. Mrayyan M.T (2006). Jordanian nurse's job satisfaction, patient's satisfaction and quality of nursing care. International Nursing Review; 53, 224-230.

3. Kunaviktikul $W$ et al (2005). Development of indicators to assess the quality of nursing care in Thailand. Nursing \& health sciences; 7(4), 273-280.

4. Hội Điều Dưỡng Việt Nam (2010). Chăm sóc Điều dưỡng, Hướng dẫn đánh giá chất lượng chăm sóc người bệnh trong các bệnh viện, Nhà xuất bản $Y$ học, Hà Nội, 9-12.

5. Bộ Y tế (2012). Chuẩn năng lực cơ bản của Điều dưỡng Việt Nam Ban hành kèm theo Quyết định số 1352/QĐ-BYT ngày 21 tháng 4 năm 2012 của Bộ $Y$ tế.

6. Nguyễn Thị Dịu (2019). Đánh giá sự hài lòng của người bệnh về công tác chăm sóc của Điều dưỡng tại Bệnh viện đa khoa Thái Thụy tỉnh Thái Bình năm 2019, Luận văn Thạc sĩ Điều dưỡng, Đại học Điều dưỡng Nam Định.

7. Shan Let al (2016). Patient satisfaction with hospital inpatient care: effects of trust, medical insurance and perceived quality of care. PloS one; 11(10), 1643-1666.

8. Aiken L.H et al (2017). Patient satisfaction with hospital care and nurses in England: an observational study. BMJ Open; 8(1), 1-8

9. Nguyễn Bá Anh, Lê Minh Hương, Bùi Kim Nhung và cộng sự (2014). Đánh giá sự hài lòng của người bệnh về chất lượng chăm sóc của Điều dưỡng tại một số khoa lâm sàng Bệnh viện Việt Đức. Tạp chí Điều dưỡng Việt Nam; 6, 9-14.

10. Ngô Thị Lan Anh, Trần Thị Chi Na và Phạm Thị Thanh Xuân (2018). Đánh giá sự hài lòng của người bệnh về chất lượng chăm sóc của Điều dưỡng tại các khoa lâm sàng Bệnh viện đa khoa tỉnh Thái Bình năm 2017. Tạp chí Y Dược lâm sàng; 108, 112119.

11. Bộ Y tế (2019). Quyết định số 3869/ QĐ-BYT ngày 28 tháng 8 năm 2019 về Ban hành các mẫu phiếu và hướng dẫn khảo sát hài lòng Người bệnh và Nhân viên y tế.

12. Bộ Y tế (2011). Thông tư số 07/2011/ TT-BYT ngày 26 tháng 01 năm 2011 Hướng dẫn công tác Điều dưỡng về chăm sóc người bệnh trong bệnh viện

13. Nguyễn Thị Tuyết Thanh (2019). Mức độ hài lòng của người bệnh đến khám tại Khoa Khám bệnh Bệnh viện Phổi Trung ương năm 2019, Báo cáo chuyên đề tốt nghiệp, Đại học Điều dưỡng Nam Định.

14. Bùi Thị Dương Vân (2011). Đánh giá sự hài lòng của người bệnh đối với hoạt động khám bệnh tại Bệnh viện Phổi Trung ương năm 2011, Luận văn Thạc sĩ Quản lý Bệnh viện, Đại học Y tế Công cộng. 